\title{
El Aerarium Militare
}

\author{
Pilar FERnÁndez URIEL
}

UNED

\begin{abstract}
RESUMEN SUMMARY
Estudio de los orígenes, fundación y

Study about the origins, foundation medios fiscales para sufragar los and fiscal sources to pay the Roman gastos del ejército Imperial romano Empire Army costs. Description of the .Exposición de las principales fuentes históricas para su conocimiento , así main historical sources and last investigation.

como las últimas investigaciones.
\end{abstract}

\section{PALABRAS CLAVE KEY WORDS}

Tributos, Aerarium, ejército, legiones, financiación, veteranii.

Taxes, Aerarium, Army, legions, financiering, veteranii.

\section{GÉNESIS DE LA FISCALIDAD MILITAR ROMANA}

Al principio ni la política exterior ni la guerra de conquista se hallaban en las preocupaciones de la administración de la Urbs. El presupuesto ordinario del Estado no contemplaba más que las defensas regulares, renovables e indispensables, que podíamos calificarles de «funcionamiento» de una ciudad- estado como era Roma conseguida por las aportaciones de los ciudadanos a través de donaciones voluntarias, réditos e impuestos indirectos, (Donationes, Reditus, Vectigalia), más o menos suficientes incluso para las necesidades de una apremiante campaña militar. 
Pronto, en una fecha no definitiva que podría situarse tal vez durante el sitio de Veyes o las Guerras Samnitas, apareció un nuevo punto presupuestario: El Stipendium, destinado a costear directamente los gastos del ejército, alimentado por una contribución especial : Tributum ${ }^{1}$.

Esta iniciativa, sin duda, se encuentra muy relacionada con las necesidades de un censo y el servicio militar de los ciudadanos, con una contribución necesaria para llevar a cabo la campaña de guerra y una cierta indemnización por estos servicios. $^{2}$

Roma ignoraba el ejército permanente, que, a lo largo de la República careció de efectivos fijos, pues se realizaban las levas militares según las necesidades. ${ }^{3}$

Entonces, el Senado votaba un Decretum conforme a la proposición de los cónsules para establecer un impuesto (Tributum) destinado a cubrir todo o parte de las necesidades del Estado y según las disponibilidades del Tesoro.

De ello se deduce:

- Su existencia y naturaleza:

Era una contribución extraordinaria, ni permanente ni regular, basada en el censo (ex censu) de la fortuna estimada a los ciudadanos (DIONISIO DE HALICARNASO, IV , 19,1-4), uno por mil de capital, aunque podía ser modificada según cuenta Tito Livio, duplex o triples (TITO LIVIO XXVII, 31,1).

Derechos legales y no una contribución y participación solidaria de los ciudadanos en una empresa colectiva, ya que en una fecha tan temprana

1 Su recaudación estaría a cargo de los Tribuni Aerarii, tema de mucha discusión. Para algunos son idénticos a los Curatores, funcionarios que, bajo organización de Servio, crearon el impuesto de guerra o (Tributum) a las tribus y el impuesto sobre el Aerarium. También actuaban como pagadores de los equites y de los soldados en servicio de cada tribu. Ver entre otra bibliografía: MARTínEZ-PINNA, J.: Los orígenes de Roma. Madrid, 1999; Sobre las condiciones del Tributum Ver: GATTI, CL.: «Riflexioni su'istituzione delle Stipendium» Acme 1970 pp. 131-135; GRELLE, F.: Stipendium vel tributum :limposizione fondiaria nelle doctrine giuridiche del II-III secolo, Nápoles, 1963; D’AMATI, N.: «Natura e fundamento del'tributum romano», Annali Fac. Giur. Bari, 1962, pp. 143-169; DI Renzo, V.: II sistema tributario romano, Capua, 1949; Brunt, P.A.: «The Fiscus and its Development», JRS, 1966, pp. 75-94; HoPKINS, K.: «Taxes and Trade in the Roman Empire» (200 B.C-A.D. 400) JRS, 70, 1980,pp. 101-125; También se trata el tema en: AA.VV.: Roman Civilization: Selected Readings, Berkeley, Columbia U.P., 1990; BRUNT, P.A.: Roman Imperial Themes, Oxford, 1990.; CARNEY, T.F.: The Economies of Antiquity, Kansas C.P., 1973. Sobre la terminología: AA.VV: Glosary of Technical Terms. Berkeley,UC.P., 2003.

2 Así el estado exigía dos tipos de participaciones: participación física al Munus militar y participación económica. Ambas estaban determinadas por el lugar del ciudadano en le censo y que los políticos e incluso los filósofos denominaban igualdad geométrica en las ciudades griegas. De estos principios se basó las fiscalidad militar romana hasta las guerras púnicas (167 a. C.) NICOLET, C. «L'ideologie du système centuriate et l'influence de la philosophie grecque», Colloquio filosofia Greca e Diritto romano, 1973, Acc. Naz. Lincei,Quaderno, 221, pp. 111-137.

3 DAVID, J.M.: «The Roman Conquest of Italy», Blackwell Publidhers, ,N.York, 1997; Según Nicolet, bastante fáciles de calcular según las necesidades esenciales de los militares: alimentación, equipamiento y soldada: 2'5 en sus comienzos:. 4 ases por día y por soldado hasta finales del siglo II a. C. y 5 ases a partir de Cesar. A partir del Imperio fue muy diferente. A partir del 211 se disparó a 80/90 denarios por año. Ver Nicolet, C.: «Armée et fiscalité:pour un bilan de la conquète romaine», Armées et fiscalité dans le monde antique C.NR.S. París, n 963 1977, pp. 446 y 447. 
como el 210 a. C., los ciudadanos se opusieron violentamente a un proyecto fiscal (una liturgia, no un tributo) que el Senado exigía por una necesidad precisa ${ }^{4}$.

- No era ni permanente ni imprescindible para los recursos económicos del Estado, sino que se mantuvo como algo que se exigía, (o solicitaba), de forma excepcional a los ciudadanos cuando se consideraba necesario. Así, en el año 167 a. C., la victoria de Paulo Emilio en Macedonia y el extraordinario botín aportado, permitió no suprimir el tributum, pero si suspenderlo provisionalmente durante más de un siglo.

- Finalmente, el tributum puede ser calificado como la llave de lo que será la fiscalidad militar en la primera fase de su desarrollo, en una concepción ciudadana de tipo relativamente arcaica con la participación política, militar y financiera de sus ciudadanos, clasificados y jerarquizados en función del Census.

\section{UNA SOCIEDAD EN CAMBIO}

Tal organización resultaba eficaz y operativa en una ciudad —estado con campañas de defensa militar limitadas en importancia y duración.

Pero este tipo de subvención ya no servía tras la conquista de Italia y mucho menos con las Guerras Púnicas, cuando Roma se enfrentó a una guerra de tipo helenístico, con las primeras conquistas trasmarinas y el proceso de construcción de su Imperio, es decir, cuando dejó de ser ciudad — estado y se convirtió en la capital de un Imperio con otras necesidades, entre otras, el mantenimiento de un poder militar permanente 5 .

Entre aproximadamente el 133 al 107 a. C., se abandonó progresivamente el ejército censatario para abordar la tropa profesional que recibía su soldada. De hecho, la llamada crisis de los Gracos y su reforma demuestra, además de un cambio social, una crisis financiera debido a los repartos frumentarios gratuitos, el equipamiento del ejército y las demandas de los mandos militares ${ }^{6}$.

4 Otro acontecimiento interesante es el del año 187-186 a. C., los amigos de Manlius Vulso consiguieron que una parte de su botín fuese entregado como compensación de una parte del tributum de años precedentes. Si bien las condiciones y la interpretación son oscuras pues el texto de Livio es muy ambiguo ( TITO LIVIO, XXXIX, 7,4-5).

5 Momigliano, A.: «Polibio, Posidonio e l'Imperialismo romano», Atti Acc. Sc. Torino,Il, 107, 1972-73, pp. 693-707 ; WebsteR, G.: The Roman Imperial Arm, Londres, 1969.

6 Se han realizado importantes investigaciones, destacan los estudios de Tenney Frank y Cl Nicolet que han abordado con precisión los gastos militares del periodo final de la Crisis Republicana ( Del 150 al 49 a. C.,basados en los notables testimonios de Polibio y Tito Livio): FRANK, T.: An economic History of Rome. T.I,N.York, 1962; NicolET, CL.: Le metier de citoyen de citoyen danas la Rome Républicaine. Paris, 1976; IBIDEM: «Tributum. Recherches sur la Fiscalité directe sous la Republique Romaine », Antiquitas, 24, 1976, pp. 200 y ss; Brunt, P.A.: Italian Manpower. 225 B.C.- A.D. 14. Oxford. 1971. 
Pero son aún más importantes las exigencias nuevas de una masa cívica, la Plebe urbana, muy numerosa, que pretendía, desde finales del siglo ॥ a. C., vivir directamente de las rentas del tesoro público acumulado («Quid tam aequum quam inoren populum vivere ex aerario suo?» FLORO, II, 1,3).

Con ello llegamos a una siguiente fase en este proceso de evolución fiscal que se opera en el mundo romano. La guerra aporta bienes pero exige el mantenimiento de la conquista y el orden impuesto, el requerimiento de su administración que reclama sueldos, indemnizaciones, distribución de dinero y de botín legal o ilegal con multitud de gastos, a la vez que debe mantener esta masa cívica.

En principio no se sufragó en la forma directa del tributum (salvo en el periodo que va desde el 43 al 36 a. C.), hubo que buscar otras formas de sufragar los gastos militares a través de cargas fiscales, bajo la forma mas o menos arbitraria de confiscaciones, tasas y contribuciones diversas impuestas a quienes pudieran pagar, a los mas ricos ${ }^{7}$.

Las guerras civiles que dieron paso al Principado, también modificaron las estructuras sociales y las militares pues los ejércitos fueron un instrumento importante y jugaron un papel decisivo en los acontecimientos brutales del final de la República cuyo proceso acabaría con la victoria absoluta de un solo protagonista: Augusto.

Y fue el propio Augusto quien tuvo que buscar la solución para el mantenimiento del ejército que consistiría en fijar los limites de las conquistas, reducir considerablemente los efectivos del ejercito y, en fin, encontrar fuentes fiscales nuevas y tolerables para los ciudadanos que deberían sufragarla y que fuesen los suficientemente considerables para alimentar de forma continuada un ejército estabilizado e instalado en las fronteras y lugares menos pacificados.

Se había pasado en menos de dos siglos de un ejército y una fiscalidad de tipo cívico a un ejército y fiscalidad de tipo Imperial $^{8}$.

\section{EL AERARIUM MILITARE: FUNDACIÓN Y DEFINICIÓN}

A Saturno, divinidad agraria y ctónica, protectora de la riqueza («Plutos:el rico»), los romanos habían confiado los bienes de los fondos públicos, depositados

7 Nicolet, CL.: op. cit 1976,pp. 200 y ss.; Fallu, E.: Cicéron et las finances publiques, Paris, 1974.

8 Frank, T.: «Augustus and the Aerarium», JRS, XXIII, 1933,pp. 143-148; GARCETTI, A.: «Aerarium e fiscus sotto Augusto. Storia di una questione in parte di nomi», Atheaeum, Studi periodici di letteratura e storia dell' Antichità. Univ. di Pavia 1953; FRANK, T.: «Augustus and the Aerarium», JRS, XXIII, 1933,pp. 143-148; Garnsey, P. and SAller, R.: The Roman Empire, Berkeley UCP, 1987; H. Jones, A.M.: The Aerarium and the fiscus. JRS, XLI, 1950,pp. 22-29; Sobre la época de Augusto hay una abundante bibliografía, ver recientemente: E.LO CASCIO, II Princeps e il suo Impero, Roma, 2000; Sobre el sistema tributario romano: FERNÁNDEZ URIEL, P.: «Algunas precisiones sobre el sistema fiscal romano» Espacio, Tiempo y Forma, Serie II, 8, 1995,pp.159-181; FERNÁNDEZ URIEL, P.: «Un fundamento en la economía de los Estados Modernos: El Sistema tributario romano. (Alto Imperio)» Aportación romana a la formación de Europa: Naciones, lenguas, culturas. Segundo coloquio de la Asociación Interdisciplinar de Estudios Romanos (AIER) 2004.pp.43-54. 
en su templo, situado en la cuesta este de la colina del Capitolio, después del destierro de los reyes, tras el asunto de Valerius Poplicola, y en él continuó hasta los últimos tiempos del Imperio (PLUTARCO. Popl. 12, Quaest. ROM. 42 ; FESTO, s.v. Aerarium $)^{9}$.

Era el «Stabulum aerarii», (tesoro-casa) la Hacienda o Caja pública de Roma, (de «Aes» latino, en su sentido derivado del «dinero»), propiedad del Senado y el pueblo romano, cuya superintendencia y administración dependía del propio Senado.

Estos tesoros públicos eran:

1. El dinero público y de las cuentas con sus correspondientes recibos, gastos, y los deudores.

2. Los estandartes de las legiones (TITO LIVIO, III,69; IV,22; VII,23)

3. Las leyes decretadas y grabadas en las tablas de bronce expuestas (SUETO.NIO, Vita Caes., 28)

4. Los decretos del Senado, que fueron inscritos allí en depósito, aunque los documentos originales fueron preservados en el templo de Ceres bajo custodia de los aediles (Fla. Josep. XIV,.10,10 ; Plut. Cat. Min. 17 ; Cic. de Leg. III,4; Tac. Anna.III,. 50 ).

5. Otros papeles y registros de importancia.

Este fue a lo largo de los periodos históricos de la Monarquía y la República el único tesoro público existente en Roma.

La primera administración financiera distinta creada en el Imperio, alimentada por fondos públicos y con otros fines diferentes, fue el Aerarium Militare.

\section{ORIGEN Y FUNDACIÓN}

Institución financiera creada por Augusto por la dificultad de la obtención de suficientes fondos de los réditos ordinarios del Estado, el Aerarium militare contenía todo el dinero acumulado y apropiado para el mantenimiento del ejército, y más concretamente como fondo que asegurase la paga, jubilación de los soldados, así como la licencia de los veteranos.

Su creación tuvo que ser fruto de un conjunto reflexiones, propuestas, medidas y consultas que comenzarían desde el 27 a. C., cuando se inicia el propio régimen augusteo, con una serie de jalones, Si bien la fecha oficial de su fundación

9 Sobre el Aerarium Militare es fundamental la obra de CORBIER, M., de la que somos deudores: L' Aerarium Saturni et l'Aerarium militare.Administration et prosopographie sénatoriales. École française de Rome.. Rome, 1974; También: CORBIER, M.: «L'Aerarium Militare». Armées et Fiscalité dans le Monde Antique. CNRS,Paris, 1977, pp.197-234. 
se cifra en el 6 d C., acabando su organización e instauración en torno al 56 con Nerón («Stipendia quoque militum et cómoda veteranorum», (SUETONIO, Vita Nero, 32, 1).

Ronald Syme en su magnifico estudio sobre Tácito sugirió que Tiberio fuera uno de los principales instigadores de la fundación del Aerarium militare : Tiberio no había invocado otro argumento que la necesidad inherente de un depósito para los gastos militares, aunque rechazaba, en principio, la imposición de nuevas tasas ${ }^{10}$.

\section{FUENTES HISTÓRICAS}

Las circunstancias en las que fue fundado el Aerarium militare son conocidas gracias a la relativa abundancia de información que contrasta con el silencio sobre el fisco Imperial. Las fuentes, aunque presentan ciertas dificultades en su interpretación, permiten complementar y conocer distintos aspectos de esta institución.

«Et M. Lep (i)do et L.Arunt(i)o co(n)s(uolibus) i(n) aerarium militare quod ex consilio $m(e o) c o(n s t i t u t) u m$ est,ex $q($ uo $)$ praemia darentur militibus, qui vicena (aut plu)ra sti(pendi)a emeruisent, HS milliens et septing(e)nti(ens ex pa)t(rim)onio (m)eo detuli».

«En el año del consulado de M. Lepidus y L Arruntius, doy de mi patrimonio 170 millones de sestercios al tesoro militar, que fue fundado de mi proposición para pagar la prima de licencia de los militares que hubieran cumplido los veinte años de servicio". Res Gestae, 17:

"Utque perpetuo ac sine dificúltate sumptus ad tuendos eos prosequendosque suppletere, aerarium militare cum vectigalibus novis constituit» (SUETONIO, Aug, 49,4)

DION CASSIO, LV, 24,9, 25,5; y 28,4-6,;LV, 31,4)

«Para subvencionar la paga de los militares y la instalación de los veteranos, Augusto constituyó un tesoro militar con la obtención de nuevos impuestos»

Según Dion Cassio, la fuente más tardía, en el año 5, Augusto plantea la necesidad de la fundación del Aerarium Militare ante el senado, con el fin de asegurar los ingresos regulares para hacer frente a las pagas militares, creándose un año más tarde, en el año 6 . El autor no sólo alude a su función, también sugiere que sus fondos fueron incluidos en diversas etapas, ya que los primeros impuestos creados resultaban insuficientes para las necesidades del ejército.

10 SYME, R.: Tacitus, Oxford, 1958, p 369; TACITO, ANN, 1,78. 
Los dos textos de Dion Cassio (LV, 25 y LVI,28 4-6) prueban que Augusto estaba decidido a arriesgarse y recurrir a impuestos directos, nuevos e impopulares, a los que, sin duda, el Senado se resistiría (Recordemos en este punto el fracaso de la reforma fiscal de Nerón, TACITO, ANN, XIII, 50, 1-2).

\section{CARACTERES}

La elección del término:

La nueva institución es una transposición entre los dos regímenes. Se integra en el cuadro preexistente de la organización financiera y recibe el nombre tradicional de Aerarium (tesoro público)La elección del término está totalmente justificada.

Para la profesora M. Corbier ofrece un ejemplo perfecto de fiscalidad militar.

Es verdad que es un tesoro en el sentido antiguo del término: Depósito.

Pero también presenta una serie de innovaciones y diferencias con el antiguo Aerarium Saturni ${ }^{11}$.

Se diferenciaba del Aerarium Saturni en varios caracteres:

- Creado por Augusto, sin ninguna atadura tradicional.

- Sus fondos eran públicos pero se alimentaban de fuentes distintas.

- Con una nueva administración financiera y gestiones económicas diferentes.

- El control exclusivo de su administración dirigida por el Princeps.

- La creación de nuevos impuestos gracias al argumento de su imperante necesidad no le restó impopularidad.

\section{ANTECEDENTE}

El antecedente más claro y directo es el Aerarium Sanctius, pero a diferencia de la estabilidad del aerarium militar, el Aerarium Sanctius era provisional ${ }^{12}$.

Bajo la República el Aerarium fue dividido en dos porciones:

- Aerarium Saturni (La Hacienda pública) común, encargado del gasto ordinario, en de el cual fueron depositados los impuestos regulares y generales

11 SUtheRLAND, C.H.V.: «Aerarium and Fiscus during the Early Empire». The American Journal of Philology, 66, 1945,pp 151-170; También: MARQUARDT, J.: «De l'organisation financière chez les Romains», T,X, Manuel des Antiquités romains, Paris, 1888; MILLAR, F.: «The Fiscus in the first centuries», JRS, LIII, 1963,pp 29-42.

12 BRUNT, A.: Italian Manpower 225 B.C. A.D. 14. OXFORD, 1971,pp 549-550; DUNCAN-JONES, R.: Structure and Scale in the Roman Economy, Cambridge U.P., 1990. 
[ Tributum, Vectigalia ], y de cuál fue tomado las sumas de dinero necesitadas para el gasto ordinario del estado

- Aerarium Sanctius o Depósito Sagrado, (TITO LIVIO,XXVII, 10, FLORO, IV, 2, CAESAR, Bellum Gallicum, 1,14; CICERON, Anuncio, Att. VII, 21), que no debía ser nunca tocado excepto en casos del peligro extremo. Probablemente fue en su origen una reserva guerra, mantenido luego como un fondo de reserva especial, ubicado también en el templo de Saturno.

Desconocemos su origen exacto. Pudo haber sido establecido después del saqueo de Roma por los Galos, para que el estado pudiera siempre tener dinero en depósito y poder resolver el peligro de un nuevo ataque a Roma, que fue temido siempre (APPIANO, B.C.,II, 41).

Al principio, probablemente, se alimentaba de una parte del pillaje ganado en sus guerras con sus vecinos pero los medios regulares para aumentarlo fueron establecidos en 357 a. C. por la Lex Manlia, que decretó que un impuesto de cinco por ciento ( vicessima ) sobre el valor de cada manumisión de un esclavo debía ser pagado a este erario. Este dinero debía ser preservado, y por lo tanto, era entregado y reservado en oro puesto que Tito Livio habla del «Vicesimarium aurum» (TITO LIVIO, VII,16 y XXVII, 10; CICERON, Anuncio Att., II,16). Al final de la época republicana, el tesoro público depositado en este Aerarium debió ser notable. Aunque saldrían importantes partidas en las guerras civiles entre Mario y Sila, cuando Julio Cesar se apropió de dicho Aerarium para su propio uso en la segunda guerra civil,(CAESAR, Bellum Gallicum,49), se asombró al encontrar depositadas sumas enormes de dinero. (PLINIO; Nat. Hist., XXXIII, 3-7; DION CASIO, XLI, 17; OROSIO, VI, 15; LUCANO, III, 155).

\section{EMPLAZAMIENTO DEL AERARIUM MILITARE}

Sin duda hubo un local donde estarían depositadas y guardadas sus reservas.

Las fuentes no dan absolutamente ninguna información o referencia sobre el emplazamiento del Aerarium Militare. M.Corbier ha sugerido el templo de la Concordia, en el Foro romano muy cercano al templo de Saturno, pero como ella misma indica es sólo una hipótesis, basada en una cita de Tacito refiriéndose al año $31 \mathrm{~d}$. C., cuando un prefecto del tesoro fue acusado de haber ofrecido a los partidarios de Sejano "Claustra aerarii cui praefectus erat militarem pecuniam", (TACITO, Ann., VI, 3,1). También allí se encontró una dedicación a la diosa en el año 10, ofrecida por un prefecto del tesoro militar ${ }^{13}$.

13 Corbier, M., op. cit., 1974, pg. 709. 


\section{FUNCIONAMIENTO Y GESTIÓN DEL AERARIUM: «PREAETORES AERARII SATURNI ET PRAEFECTI AERARII MILITARI»}

Augusto organizó los dos cuerpos de funcionarios (Aerarii públici), cuya administración fue consolidada por sus sucesores.

En el año 28 a. C. Augusto nombró 2 praetores Aerarii Saturni (TACITO, ANN, I, 75; FRONTINO, De Aquae Duct, 100. En el año 23 a. C. asumen esta prefectura del Erario de Saturno dos de los pretores en ejercicio ese año. (ORELLI, Inscr. N. $\left.{ }^{\circ} 723\right)$.

Esta organización del Aerarium se continuó hasta el principado de Claudio que los volvió a convertir en los dos Quaestores aerarii, según la tradición republicana, permaneciendo tres años en servicio y privándolos de ciertas "Officinae» que habían recibido de Augusto (TACITO, ANN, XIII, 29; SUETONIO, Vita. Claud. 24 ; Dion Cass. LX.24 ).

Nerón volvió a la original forma de Augusto, aunque, si bien volvió a confiarlo a los que habían sido Praetores, que pasaron a recibir el título del Praefectii aerarii, (TACITO, ANN, XIII, 28,29). Durante la última parte de su principado o al principio del de Vespasiano, parece haber sido realizado nuevo cambio, porque vuelven a aparecer como Praetores aerarii, (TACITO, Hist. IV,9). Durante el principado de Trajano, si no antes, y tan solo por dos años fue confiado otra vez a los Praefectii, como parece haber sostenido su «officina» y en adelante no volvió a realizarse ningún otra modificación. (PLINIO, Paneg., 91,92; Ep. x. 20; $)^{14}$.

Los Praetores Aerarii Saturni pudieron contar con Quaestores que ayudaban y les asesoraban en sus deberes, pues hay menciones de Quaestores en el Aerarium Saturni en inscripciones de Hadriano y de Severo (GUDIO, Ant. Inscr. p125, $\mathrm{N}^{\circ}$ 6, p131 n3; GRUTER, p1027, N. ${ }^{\circ}$ 4; PLINIO, Paneg. 36; Tit. 14 ss13, 15, 49).

En el año $6 \mathrm{~d}$. C. Augusto nombró los praefecti aerarii militari que formaban un colegio de tres senadores de rango pretorio que ejercían su cargo durante tres años a quienes se asignaba el gobierno y administración de la caja militar. Este colegio permaneció invariable durante dos siglos.

Los Tresviri, nombrados por el Princeps, servían directamente al emperador tres años sin salir de Roma y solo a él debían rendir cuentas de su gestión.

Eran por lo tanto senadores que antes habían ejercido el cargo de Praetor, (Dion Cass. LV,25; TACITO, Ann. V.8), Contaban con experiencia administrativa,

${ }^{14}$ Durante la República, el Aerarium Saturni estaba a cargo de los Quaestores urbanos bajo el control del Senado, así continuó, excepto en el 45 a. C., cuando no se eligió ningún Quaestor,.Dos prefectos de la ciudad se ocuparon del Aerarium, (Dion Cass. XLIII.48) ; pero pasó otra vez a manos de los cuestores, cuando fueron elegidos en el año siguiente hasta que Augusto transfirió el aerarium a los dos Praefecti Aerarii elegidos anualmente por el Senado. CÉBEILLAC, M.: Les <quaestores principis et candidati > aux I-II siècles de l'Empire, Milan, 1974; ForTINA, M.: «I <Praefecti Aerarii Saturni>» Rivista di Studi Classici, IX, 1961,pp 217-234. 
jurídica y militar, lo cual ofrece una cierta información de la actividad de su cargo, pues la documentación es escasa y no es muy frecuente encontrar en las inscripciones el titulo de Praefecti aerari militarii. (TACITO, Ann. XIII 29) ${ }^{15}$.

Las atribuciones de los tres responsables del Aerarium militare ni se interferían ni restringían las de los del Aerarium Saturni, pero siempre esta última era la que precedía cuando las dos prefecturas encontraban en un mismo Cursus Honorum. Se trataba de las siguientes:

Duración trienal de su cargo.

Prefectura de rango senatorial.

Elegidos por una comisión de senadores reunida y convocada por el Princeps.

Reclutados entre antiguos Praetores.

Augusto tuvo ya un especial interés de que llevaran un servicio financiero por lo que se interesó que fueran personas preparadas para su gestión

En el 56 Nerón dio el estatuto definitivo a la gestión del tesoro público.

Los senadores encargados de una y otra caja tenían una indudable preparación para abarcar las competencias administrativas y financieras exigidas, pero además los Praetores Aerarii militarii, debían demostrar su capacidad militar, lo que subraya la identidad y actividad de la institución. Entre los tres prefectos, se incluía siempre uno de ellos procedente del Cursus honorum militiae, un senador que después de la pretura haya asumido directamente el mando de una legión (vir militare).

A pesar de la innegable importancia de ambos cargos y su paralelismo, al menos hasta los Severos hubo diferencias entre ellos. M.Corbier sugiere que el Cursus de ambos se realizarían de forma paralela y serían muy semejantes sus competencias administrativas y financieras. Incluso, el personal de servicio sería semejante, con funcionarios y escribas familiarizados y expertos en sistemas tributario y financiero, además del pago y licencia d e soldados.

Desde Vespasiano a Cómmodo, la administración del Aerarium militare podía conducir al consulado sufecto previo ejercicio de una magistratura superior. Sin embargo la dirección del Aerarium Saturno, si confería el acceso directo a dicho consulado.

Con Trajano y Adriano, las prefectura financiera se confíaron a Homines Novi, elegidos por el Principe ${ }^{16}$.

15 Walter, Geschichte des Römischen Rechts, pp 201, 397, 2d edition.

16 Corbier, M.: «Devaluation et fiscalité (161-235)», en Les dévaluations à Rome. Collection de l'écle française de Rome, 37, (1978), p. 273 y ss. RathBONE, D.W.: «The Imperial Finances», The Cambridge Ancient History, Ed. Alan Bowman, Ed. Champlin —Andrew Lintott, Vol. X, 2 ed. Cambridge U.P., 1996,pp. 300 y ss. 


\section{LA FINALIDAD DEL AERARIUM MILITARE Y SU SOLVENCIA. INGRESOS Y GASTOS}

\section{Ingresos}

La originalidad y la base de la institución reside en la puesta en marcha de un sistema que asegurara unos ingresos regulares y Augusto fue inflexible en esta decisión Estos ingresos pueden clasificarse.

1. Dotación inicial: Fue dotado en gran parte por el emperador mismo. Augusto pagó una suma muy grande al Aerarium Militare en su fundación, que prometió hacer cada año. En el Monumentum Ancyranum, Augusto informa haber pagado en el consulado de Emilio y de Arruntio 170 millones de sestercios; pero esta suma es probablemente la cantidad entera entregada a lo largo de su gobierno. (DION CASIO, LV, 25,3; RES GESTAE, 17):

«En el año del consulado de M. Lepidus y L Arruntius, doy de mi patrimonio 170 millones de sestercios al tesoro militar, que fue fundado de mi proposición para pagar la prima de licencia de los militares que hubieran cumplido los veinte años de servicio».

Se ha calculado que, como su principado duró ocho años y medio, tras el establecimiento del Aerarium Militare, y habría hecho probablemente los pagos cada seis meses, posiblemente pudo haber contribuido con diez millones de sestercios cada medio año. M.Corbier lo ha calculado en base a cuatro años, con una dotación de 40 millones de sestercios anuales. También se ha calculado que este capital podía financiar la licencia del ejército de 14.000 veterani.

2. Tributación: La solvencia de estos fondos quedaban asegurados por la introducción de nuevos impuestos que ya él mismo decretó para ser integrados en dicho aerarium,(SUETONIO, VIta Aug.,49;DION CASIO, LV, 23,24,25 y 32; Monumentum Ancyranum, pp. 32 y 65, ed. Franzius y Zumptius, Berol. 1845).

Apoyaban a estos ingresos:

- El impuesto sobre ventas públicas y el deber de sucesión. De éstos el más importante era la vicessima hereditatum et legatorum, un impuesto de cinco por ciento, que tuvieron que ser pagados por cada ciudadano romano sobre cualquier herencia o legado recibido, a excepción de que se tratara de los parientes más cercanos, o estar por debajo de cierta cantidad (DION CASIO,. LV.25;y LVI,28;PLINIO, Paneg. 37, 40 ;CAPITOLINO, His. Aug.,11 ). Este impuesto fue aumentado por Caracalla a diez por ciento, pero reducido posteriormente por Macrino a cinco (DION CASIO, LCCVII, 9; LXXIII, 12) ${ }^{17}$.

17 GiLliam, J.F.: «The minimum Subject to the Viccessima Hereditatum», AJPh. 1952, pp. 398 y ss; Bıond, B.: Sucessione testamentaria e donazione in Roma antica, Milan 1955. 
- El impuesto de un uno por ciento sobre cada objeto vendido en las subastas (Centesima rerum venalium), reducido por Tiberio al cero cincuenta por ciento ( ducentesima ), y suprimido luego por Caligula para la península Itálica (TACITO,. ANN.I,78; II, 42; SUETONIO, V ita Caius. 16).

- En el año 7 se añade otro impuesto suplementario (Tasa de ventas de esclavos), Se estableció un impuesto sobre cada esclavo comprado, al principio de un dos por ciento, (quinquagessima), y luego de cuatro por ciento ( quinta et vicessima) de su valor (DION CASIO,LV,31; TACITO ANN. XIII, 31; Orelli, Inscr. No. 3336) (Tal vez debido a la incorporación del cuerpo de vigiles, recientemente constituido (Calculando 30 legiones: 180.000 legionarios) ${ }^{18}$.

- En el 13 se propone un nuevo impuesto sobre las tierras y las casas, (Fundi et Domi) según Dion Casssio.

3. Finalmente, se ingresaron en dichos fondos las contribuciones voluntarias de algunos reyes aliados y comunidades no precisadas por Augusto.

\section{LA ESTIMACIÓN DE LAS NECESIDADES. LOS GASTOS}

Las fuentes son mucho menos explícitas todavía en la información relativa a los gastos y pagos que se efectuaban a través del Aerarium Militare. Son muchas las cuestiones planteadas.

En primer lugar habría que diferenciar claramente los términos utilizados (Commoda y Praemia militare).

En segundo lugar, como ya advertía M. Corbier, hay que interpretar la posible contradicción entre las información que proporciona las Res Gestae y la citas de Suetonio y Dion Cassio, fuentes fundamentales para conocer el Aerarium militare si esta nueva caja era en principio para pagar los «Praemia militae» de los Veteranii o a todos los soldados.

En principio, sirvió sólo para pagar las licencias de los veteranos:

«Ex q(uo) praemia darentur militibus, qui vicena (aut plu)ra sti(pendi)a emeruisent: para pagar la prima de licencia de los militares que hubieran cumplido los veinte años de servicio». Res Gestae, 17:

Sin embargo, las referencias de Suetonio y Dion Casio parecen indicar otro tipo de gastos.

Dion Cassio no solo no hace apenas alusión a quienes iba destinada, sino que parece indicar que iba a pagar la totalidad de las expensas militares.

18 LuZZATto, V.: «La riscossione dei tributi in Roma e l'ipotesi della propietà soverana»., Atti dei Congresso di diritto romano. Verona, 1948. pp. 210 y ss. 
«Para subvencionar la paga de los militares y la instalación de los veteranos, Augusto constituyó un tesoro militar con la obtención de nuevos impuestos «(DION CASSIO, LV, 24,9).

"Utque perpetuo ac sine dificúltate sumptus ad tuendos eos prosequendosque suppleteret, aerarium militare cum vectigalibus novis constituit «SUETONIO, Aug, 49,3 y 4$)$.

¿Sueldos, pensiones, subvenciones, o solamente licencias? Dicho de otra manera ¿Se contemplaba solamente pagar a los veteranos o a todos los militares?.

Es posible que, en un principio solo se buscó asegurar la licencia y Praemia de los veteranos, para, más adelante, pagar a todos los soldados, de ahí la cita relativa a Nerón : (SUETONIO, Nero, 32,1 «Stipendia quoque militum et cómoda veteranorum»).

Todo ello plantea una serie de cuestiones en torno a los Praemia y Commoda militari:

Es posible que, además de los Praemia militiae, se contemplaban las indemnizaciones a los soldados mutilados que cita Suetonio, con la posibilidad de otro tipo de ayudas y pensiones que abarcaría el término Commoda veteranorum.

\section{PRAEMIA MILITARE}

Otro problema suscitado y aún no resuelto es el cálculo aproximado de estos gastos y su naturaleza.

El cumplimiento del servicio militar completo en su duración legal (Honesta missio), tenía como garantía la licencia con una recompensa (Praemia militare), tierras para instalarse y cultivar, que según la mayoría de los autores pasaría a convertirse en dinero. Aunque, posiblemente este capital estaba fijado, su cantidad variaba según el rango militar y el grado de ciudadanía del soldado licenciado ${ }^{19}$.

G. Forni ya planteó la cuestión de la donación de tierras o dinero a los Veteranii en el siglo I.

Durante la República y la época Augustea, el Estado tenía que disponer de un Stock de tierras para su asignación gratuita o a un precio muy bajo a los colonos militares, ya consolidado como derecho. (DION CASSIO, LIV, 25,5) ${ }^{20}$.

19 Watson, G.R.: «Discharge and Resettlement in the Roman Army. The <Praemia Militiae>, Neue Beiträge zur Geschichte der Alten Welt,Römisches Reich,II, Berlin 1965, pp. 152.; WATSON, G.R.: The roman Soldier, Bristol, 1970, pp 97-98.

20 Ver ERdkamp, P.: The Roman Army and the Economy, Amsterdam, 2002 ; También ForNI, G.: II reclutamento delle legioni da Augusto a Diocleziano. Roma, 1953. 
Después de Augusto, con sus sucesores, la situación cambió, ya por la escasez de dichas tierras, ya porque los mismo Veteranii se negaban a cultivar una tierra, generalmente baldía en una provincia inhóspita, (TACITO, ANN, I, 17,5).

Por otro lado hay que analizar diversos factores: número de soldados, su condición y rango militar ya que según estas condiciones se realizaría su licencia ya que las fuentes no son claras sobre estas cuestiones.

Otro tipo de cálculo necesario es la cantidad de soldados a pagar e indemnizar. La edad del veterano, calculando la media de vida, (unos 40 años), con ya 20 años de servicio, se calcula que restaban una media de 8 años de vida, a lo que habría que descontar una media entre el 50 y el $60 \%$ de soldados que lograrían finalizar su servicio y licenciarse ${ }^{21}$.

\section{EVOLUCIÓN Y DECADENCIA}

Augusto procedió a la fundación y organización del Aerarium Militare en diversas fases y las últimas fueron cubiertas por sus sucesores Julio Claudios.

A su vez, el Aerarium romano también sufrió el proceso evolutivo del propio Principado.

El ejército representó una parte importante y sin duda mayoritario de los gastos del Estado, junto con los salarios de los funcionarios civiles, además de otras partidas: "Annona», trabajos y diversas construcciones, espectáculos públicos (Ludi romani) etc. Dichos gastos militares variaron bastante y con frecuencia, por lo que provocaron desequilibrio financiero. glos.

El aerarium militare funcionó prácticamente sin modificaciones durante dos si-

Con Marco Aurelio y sobre todo con Cómmodo se inicia la decadencia del Aerarium militare y a partir de Severo Alejandro es ya clara su declive paralelo al del Aerarium Saturni.

Es difícil definir el final del Aerarium Militare. Debió desaparecer en la segunda mitad del siglo III, ya que M.Corbier ya no encuentra referencia de los Praetores Aerarii Militarii.

A partir de dicha fecha, concretamente, en el 360 , finaliza su cargo el último prefecto del tesoro conocido.

Duraría más algo más tiempo la actividad del Aerarium Saturno, cuyos pretores ejercieron su cargo hasta final del IV, desapareciendo tras el gobierno de Cons-

21 J.d 'Encarnaçao: «Morrer a los cuarenta annos» Actas del Coloquio sobre la Lusitania romana. Mérida, 2204, $p$. 
tantino y Constancio II. El último prefecto del Aerarium Saturno fue Flavius Attilius Theodatus, que finalizó su cargo en el 380. A partir de entonces su gestión fue remplazada jóvenes cuestores.

Se sabe que en le Bajo Imperio esta cuestura estaba decadente y depreciada, vacía de responsabilidades y atribuciones por lo que no se necesitaba experiencia para su desempeño. Los funcionarios imperiales acabarían sustituyendo a los cuestores y a los curatores en los archivos y erarios del Estado romano.

A partir d el siglo IV, (384) el término Aerarium es sustituido por los de Arca Quaestoria y Fisco Imperial.

Los emperadores últimos tenían un Patrimonium privatum separado del aerarium, conteniendo el dinero asignado para su propio uso, distinto del fiscus, que administraron en los intereses del imperio ${ }^{22}$.

\section{CONCLUSIONES}

El régimen Imperial dio lugar al paso a un ejército permanente e institucional bajo las órdenes directas del Princeps, que, siguiendo los pasos de los grandes militares de la crisis republicana, se vinculaba con sus propios soldados y debía asegurarles su beneficio tras la victoria en el combate, bien en tierras o dinero para facilitar su reinserción en la vida civil.

Con la diferencia, que el Princeps no debía utilizar tales circunstancias en su único y propio provecho, pues se había convertido en un ejército de paz y no de guerra, era una fuerza militar nueva en una sociedad civil renovada donde se brindaba la estabilidad, el orden, la regularidad, Fue un importante instrumento del nuevo estado y del régimen imperial y de de gran utilidad para el Principado.

El Aerarium militar fue, sin duda un ambicioso proyecto, su mejor conocedora, M.Corbier advierte la necesidad de plantearlo en un contexto más general: En la evolución del propio ejército romano.

Pero si analizamos sus servicios y las causas que motivaron su fundación advertimos una serie de caracteres:

Desmovilización masiva de efectivos, para, progresivamente, reducir y estabilizar a los veteranos, a fin de legalizarlos y establecerlos en una sociedad civil.

Trasformar soldados en profesionales de la vida militar con sueldo y otras ventajas con tasa oficiales establecidas y respaldadas por el Estado.

22 Nesselhauf, H.: Patrimonium und res private des römischen Kaisers Hsitoria Augusta Colloquium, Bonn, 1963,pp 73-93. 
También se encontraron extorsiones y problemas. Tal vez el más importante fuera el riesgo de la impopularidad de crear impuestos nuevos (TACITO, ANN.,XIII, $50,1-2)$.

Aún así, estos impuestos pueden ser considerados como una contribución simbólica de la sociedad que compartía con el Príncipe la responsabilidad ciudadana de un ejército renovado. Se trataba de una autentica necesidad no solo militar sino social para contribuir y participar con el Princeps a su responsabilidad hacia el ejército ${ }^{23}$.

Por ello tal vez el Aerarium militare podría analizarse en un contexto aún mayor que el que propone la Dra. Corbier: La sociedad romana, en la que el ejército tuvo que servir e integrarse con otras exigencias y servicios. Dicho de otras manera: Porque siempre en la Historia a una nueva sociedad, le corresponde una nueva ideología y una nueva cultura, y con ello, un nuevo ejercito.

\section{BIBLIOGRAFÍA}

AA.VV: Glosary of Technical Terms. Berkeley, UC.P. 2003.

AA.VV. Roman Civilization: Selected Readings, Berkeley, Columbia U.P., 1990.

BıONDI, B.: Sucessione testamentaria e donazione in Roma antica, Milan 1955.

BRunt, P.A.: «The Fiscus and its Development», JRS, 1966, pp 75-94.

Brunt, P.A.: Italian Manpower. 225 B.C.- A.D. 14. Oxford. 1971.

- : Roman Imperial Themes, Oxford, 1990.

CARnEY, T.F.: The Economies of Antiquity, Kansas C.P., 1973.

CÉBEILLAC, M.: Les «quaestores principis et candidati» aux I-II siècles de l'Empire, Milan, 1974.

Corbier, M.: «Devaluation et fiscalité (161-235)», en Les dévaluations à Rome. Collection de l'école française de Rome, 37, (1978),p. 273 y ss.

CRAWFORD, M.: «Money and Exchange in the Roman World», JRS, 60, 1970, pp 40-48.

C.H.V. SUTHERLAND: «Aerarium and Fiscus during the Early Empire». The American Journal of Philology, 66, 1945,pp 151-170.

CORBIER, M.: L'Aerarium Saturni et l'Aerarium militare.Administration et prosopographie sénatoriales. École française de Rome.. Rome, 1974.

CorbieR, M.: «L'Aerarium Militare». Armées et Fiscalité dans le Monde Antique. CNRS, Paris, 1977, pp.197-234.

D'AMATI, N.: «Natura e fundamento del'tributum romano», Annali Fac. Giur. Bari, 1962, pp. 143-169.

DUNCAN-JONES, R.: Structure and Scale in the Roman Economy, Cambridge U.P., 1990.

ERDKAMP, P.: The Roman Army and the Economy, Amsterdam, 2002.

FALLU, E.: Cicéron et las finances publiques, Paris, 1974.

FERnÁNDEZ URIEL, P.: «Algunas precisiones sobre el sistema fiscal romano» Espacio, Tiempo y Forma, Serie II, 8, 1995, pp.159-181.

FERNÁNDEZ URIEL, P.: «Un fundamento en la economía de los Estados Modernos: El Sistema tributario romano. (Alto Imperio)» Aportación romana a la formación de Europa: Naciones, lenguas, culturas. Segundo coloquio de la Asociación Interdisciplinar de Estudios Romanos (AIER) 2004.,pp. 43-54.

FINLEY, M.: The Ancient Economy, Berkeley ;U.C.P, 1999.

FoRNI, G.: II reclutamento delle legioni da Augusto a Diocleziano. Roma, 1953.

FortinA, M.: «I <Praefecti Aerarii Saturni>» Rivista di Studi Classici, IX, 1961, pp 217-234.

FRANK, T.: «Augustus and the Aerarium», JRS, XXIII, 1933, pp. 143-148.

GARCETtI, A.: «Aerarium e fiscus sotto Augusto. Storia di una questione in parte di nomi», Atheaeum, Studi periodici di letteratura e storia dell’ Antichità. Universidad di Pavia 1953.

${ }^{23}$ WHITTAKER, R.: «The consumer city revisited: the vicus and the city», Journal pf Roman Archeology, $3,1990, p 110$ y ss. 
Garnsey, P. and Saller, R.: The Roman Empire, Berkeley UCP, 1987.

GARNSEY, P.: Taxatio and Pollicitatio in Roman Africa, JRS, 61, 1971, pp 116-129.

GATTI, C.L.: «Riflexioni suu'istituzione delle Stipendium» Acme 1970 pp. 131-135.

GILLIAM, J.F.: «The minimum Subject to the Viccessima Hereditatum», AJPh. 1952, pp 398 y ss.

GRELLE, F.: Stipendium vel Tributum.L'imposizione fondiaria nelle doctrine giuridiche del II -III secolo.Napoles, 1963.

HARMAND, J.: L'armée et le soldat à Rome de 107 à 50 avant n.è. Paris, 1967.

HOPKINS, K.: Taxes and Trade in the Roman Empire (200 B.C-A.D. 400) JRS, 70, 1980,pp. 101-125.

HowgEGo, C.h.: «The Supply and Use of Money in the Roman World 200 B.C- A.D. 300», JRS, 82,1992, pp.1-31.

H. JONES, A.M.: The Aerarium and the fiscus. JRS, XLI, 1950, pp. 22-29.

Lo CASCIO, E.: Il Princeps e il suo Impero, Roma, 2000.

LUZZATTO, V.: «La riscossione dei tributi in Roma e l'ipotesi della propietà soverana». Atti dei Congresso di diritto romano. Verona, 1948.pp. 210 y ss.

Mann, M.: The Sources of Social Power. Cambridge U.P., 1986.

MARQUARDT, J.: De l'organisation financière chez les Romains, T,X, Manuel des Antiquités romains, $\mathrm{Pa}$ ris, 1888.

Martinez-PINNA, J.: Los orígenes de Roma. Madrid, 1999.

MILLAR, F.: «The Fiscus in the first centuries», JRS, LIII, 1963,pp 29-42.

MomigliAno, A.: «Polibio, Posidonio e l'Imperialismo romano», Atti Acc. Sc. Torino,II, 107, 1972-73, pp. 693-707.

Nesselhauf, H.: Patrimonium und res private des römischen Kaisers Historia Augusta Colloquium, Bonn, 1963, pp 73-93.

Nicolet, C.L.: Prosopographie et Histoire sociale: Rome et l'Italie à l'époque républicaine. Annales E.S.C. $25 .^{\circ}$ année, 1970 , pp. $1209-1228$.

Nicolet, C.I.: Tributum. Recherches sur la Fiscalité directe sous la Republique Romaine. Bonn,. Antiquitas, 24,1976 , pp. 200 y ss.

NiCOLET, CL: Le metier de citoyen de citoyen dans la Rome Républicaine. Paris, 1976.

NICOLET, CL: «L'ideologie du système centuriate et l'influence de la philosophie grecque», Colloquio FiIosofia greca e Diritto Romano, 1973, Acc. Naz. Lincei.Quaderno 221, 1976, pp 111-137.

Nicolet, CL: «Armée et Fiscalité:pour un Bilan de la Conquête romaine. Armées et Fiscalité dans le Monde Antique.CNRS, Paris, 1977, pp.435-452.

Rathbone, D.W.: «The Imperial Finances», The Cambridge Ancient History, Ed. Alan Bowman, Ed. Champlin —Andrew Lintott, Vol. X, 2 ed. Cambridge U.P., 1996,pp. 300 y ss.

SUTHERLAND, CHV.: «Aerarium and Fiscus during the Early Empire», The Americam Journal of Philology, ,Vol. 66, 2 1945, pp. 151-170.

SYME, R.: «People in Pliny», JRS, LVIII, 1968,pp 135-169.

SHERWIN-WHITE, N.: The Roman Citizenship, 1973.

SHERWIN-WHITE,A.N.: The letters of Pline. A Historical and social Commentary, Oxford, 1966.

WATSON, G.R.: "Discharge and Resettlement in the Roman Army. The <Praemia Militiae>, Neue Beiträge zur Geschichte der Alten Welt, Römisches Reich,II, Berlin 1965, pp. 152.

WATSON, G.R.: The roman Soldier, Bristol, 1970, pp 97-98.

Webster, G.: The Roman Imperial Army, Londres, 1969.

WhITTAKER, C.R.: Land, City and Trade in the Roman Empire, N.York, 1993.

WHITTAKER, C.R.: «Trade and the aristocracy in the Roman Empire», Opus. International Journal for Social and Economic History of Antiquity, 4, 1988, pp. 55 y ss.

WHITTAKER, C.R.: «The consumer city revisited: the vicus and the city», Journal pf Roman Archeology, 3, 1990,p 110 y ss. 